\title{
Supplementary Information for \\ Low temperature calorimetry coupled with molecular simulations for an in-depth characterization of the guest-dependent compliant behaviour of MOFs
}

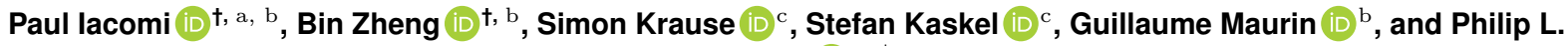
Llewellyn (iD) ${ }^{\text {a, }}$

† These authors contributed equally

*E-Mail: philip.llewellyn@univ-amu.fr 


\section{Contents}

1 Low temperature calorimetry setup $\quad$ S3

2 Recorded isotherms $\quad$ S4

3 Recorded enthalpy curves $\quad$ S5

4 Evidence for quasi-equilibrium operating conditions $\quad$ S6

$\begin{array}{llr}5 & \text { Physical properties of guest gases } & \text { S6 }\end{array}$

6 Lennard-Jones parameters for MC simulations $\quad$ S7

$\begin{array}{lll}7 & \text { MC snapshots at different pressures } & \text { S7 }\end{array}$

8 Dataset of deconvoluted nitrogen isotherms $\quad$ S8

9 Material colour change and degradation with adsorption $\quad$ S9

10 Time-resolved enthalpy data and integration at $77 \mathrm{~K} \quad \mathrm{S10}$

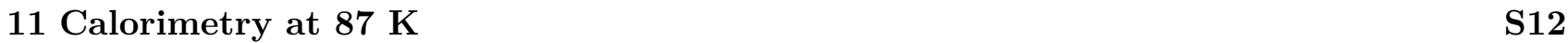




\section{Low temperature calorimetry setup}

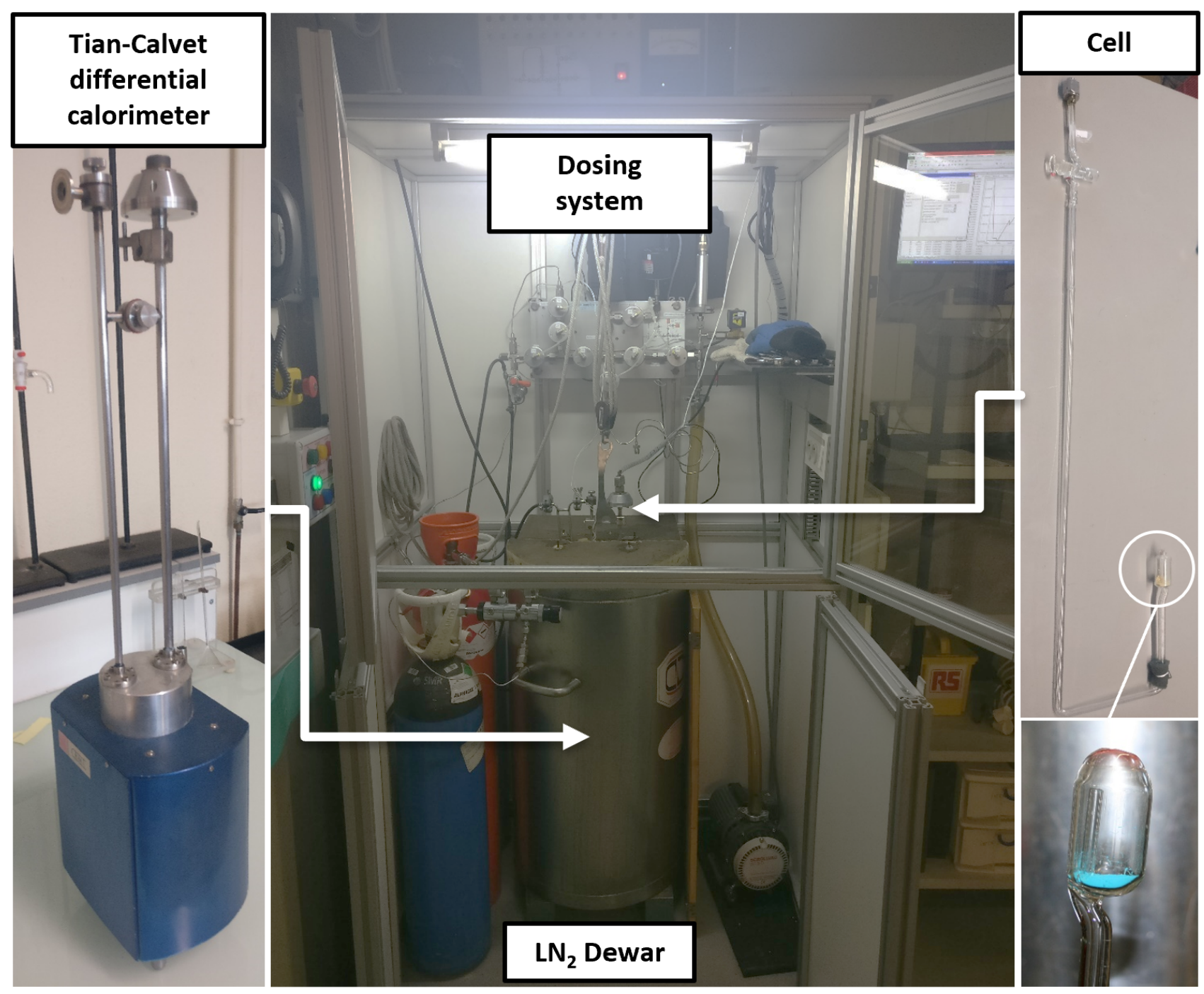

Fig. S1. Low temperature calorimetry apparatus used to record combined isotherm and enthalpy measurements. (left) Tian-Calvet home-made calorimeter in an inverted diving bell configuration. (middle) Experimental setup, with calorimeter submerged in a Dewar filled with cryogenic fluid, liquid nitrogen or argon, connected to the upper automated dosing system and helium supply, kept in a temperature-controlled enclosure. (right) Borosilicate glass cell used to contain sample, inserted into the calorimeter and connected to the dosing system during normal operation. 


\section{Recorded isotherms}
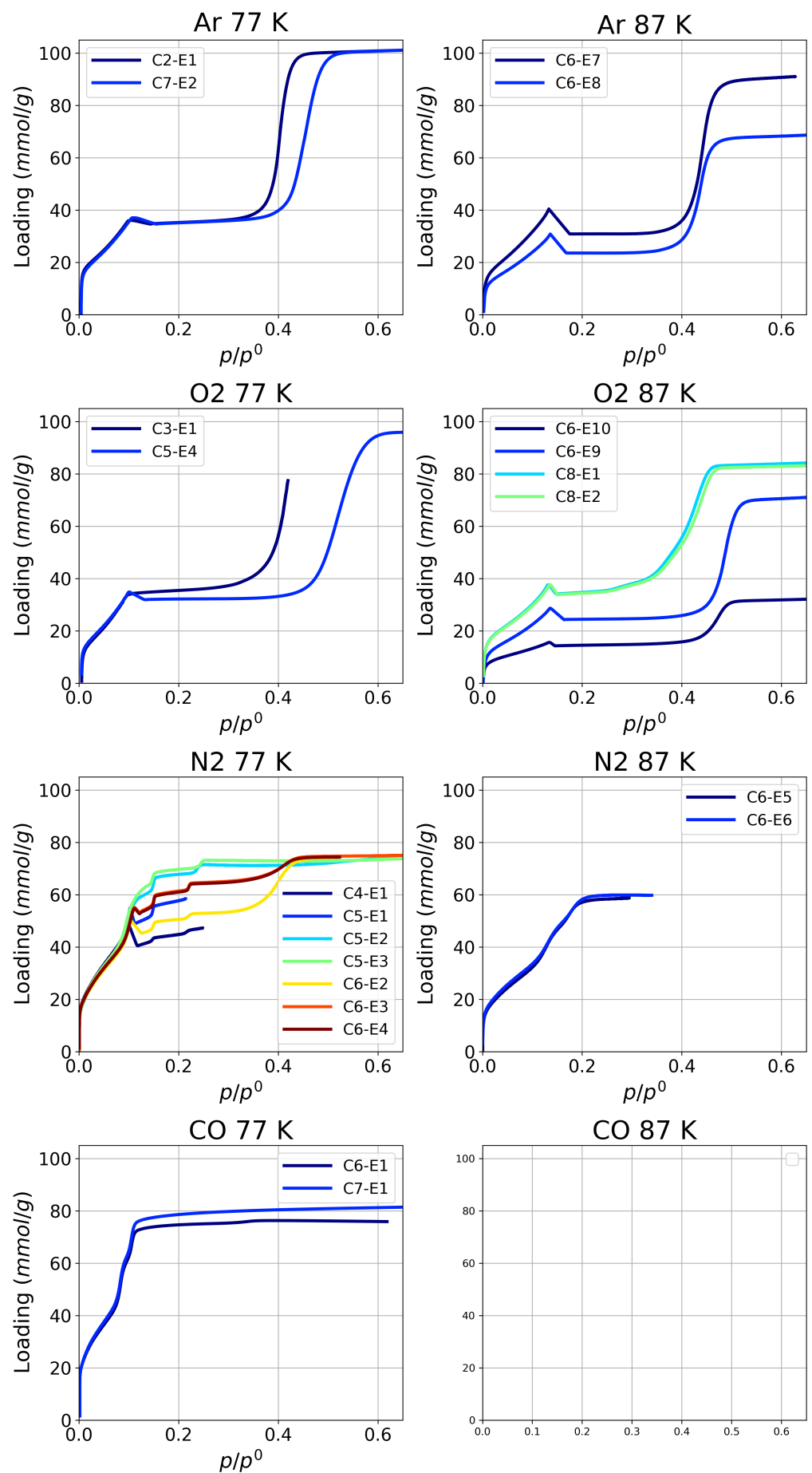

Fig. S2. Low temperature calorimetry isotherms recorded throughout this study for (left) $77 \mathrm{~K}$ and (right) $87 \mathrm{~K}$. The legend specifies the id of the glass cell prepared (C1 to $\mathrm{C} 8$ ) and the experiment number on each cell. 


\section{Recorded enthalpy curves}
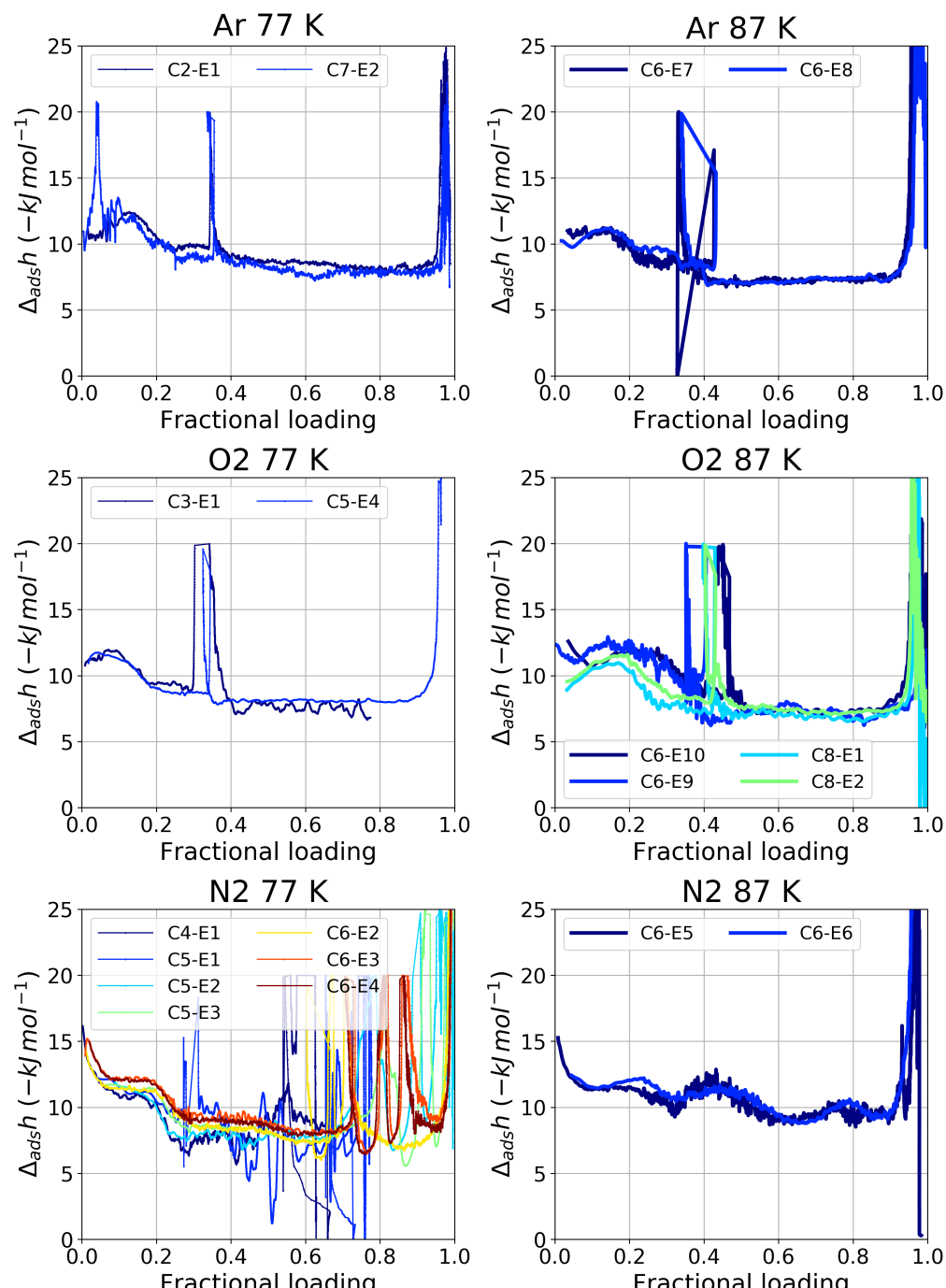

$\mathrm{N} 287 \mathrm{~K}$
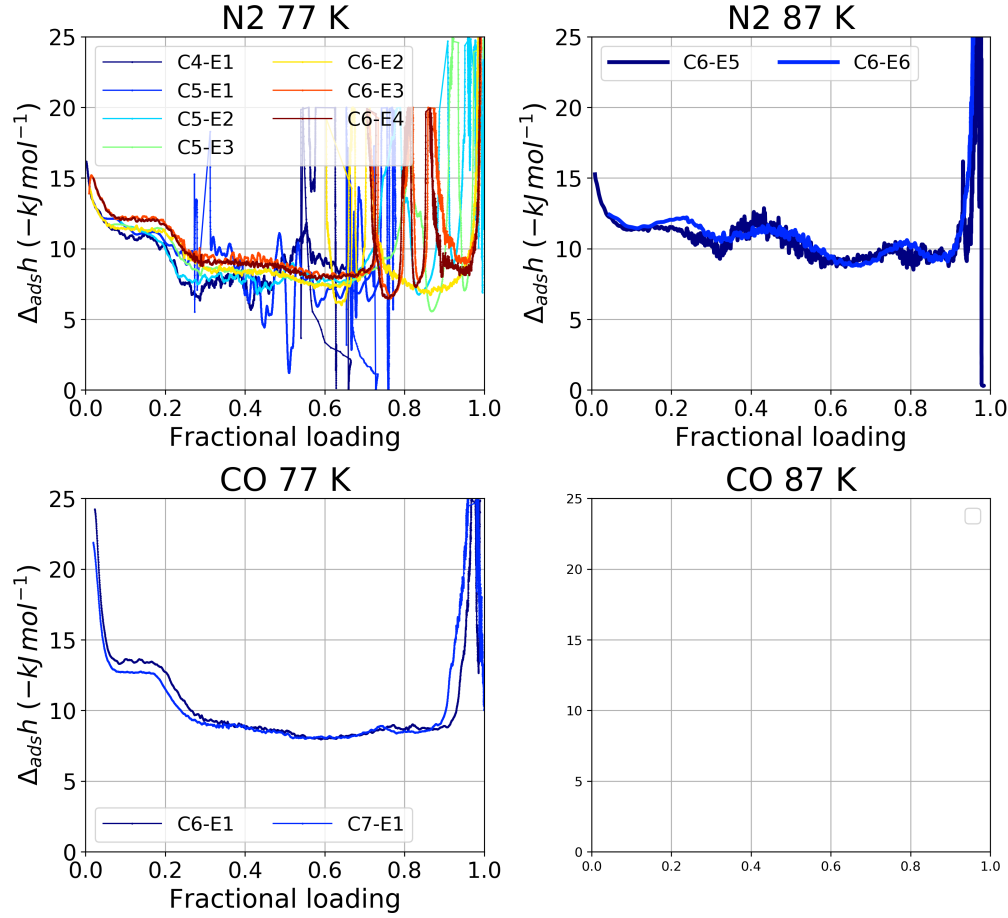

Fig. S3. Low temperature calorimetry enthalpy curves recorded throughout this study for (left) $77 \mathrm{~K}$ and (right) $87 \mathrm{~K}$. The peaks corresponding to the structural transition are trimmed above $20 \mathrm{~kJ} \mathrm{~mol}^{-1}$. The legend specifies the id of the glass cell prepared (C1 to C8) and the experiment number on each cell. 


\section{Evidence for quasi-equilibrium operating conditions}

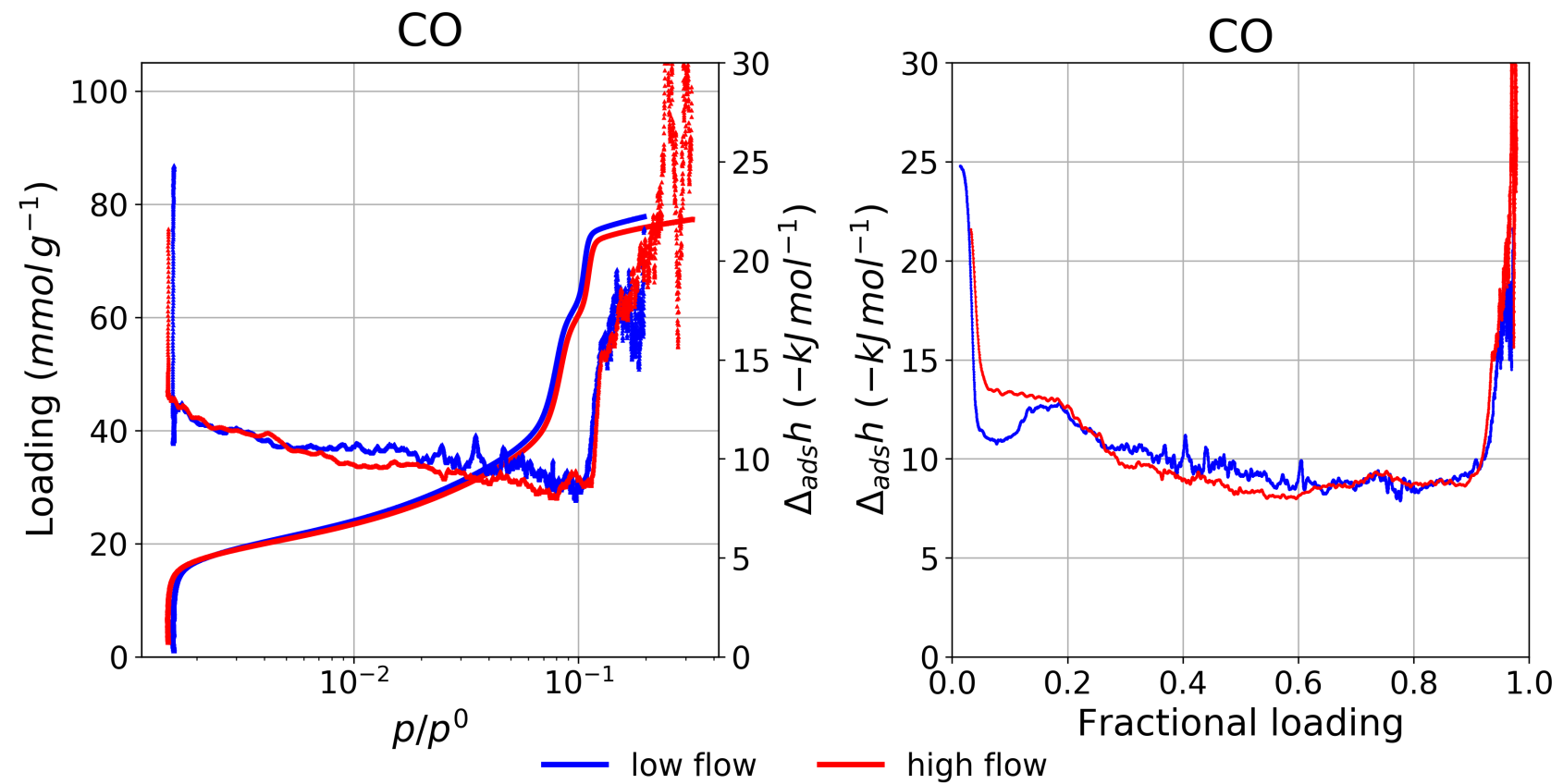

Fig. S4. Comparison between low and high flowrate experiments performed with carbon monoxide with high (red) and low (blue) flow on the same experimental sample. The two resulting isotherms and enthalpy curves are nearly identical, confirming that the experiment is taking place below the dead time of the calorimeter. A lower signal to noise ratio is observed in the high flow curve, due to the quicker experimental duration.

\section{Physical properties of guest gases}

Table S1. Properties of probe gases used at $77 \mathrm{~K}$.

\begin{tabular}{|c|c|c|c|c|}
\hline Probe & $\mathrm{Ar}$ & $\mathrm{CO}$ & $\mathbf{N}_{2}$ & $\mathrm{O}_{2}$ \\
\hline $\begin{array}{c}\text { molar mass } \\
\mathrm{g} \mathrm{mol}^{-1}\end{array}$ & 39.948 & 28.010 & 28.0134 & 31.999 \\
\hline $\begin{array}{c}\text { boiling point @ } 1 \text { atm } \\
K\end{array}$ & 87.4 & 81.6 & 77.35 & 90.19 \\
\hline $\begin{array}{l}\text { cross-sectional area } \\
\mathrm{nm}\end{array}$ & 0.138 & 0.168 & 0.162 & 0.141 \\
\hline $\begin{array}{c}\text { polarizability } \\
10^{-3} \mathrm{~nm}^{3}\end{array}$ & 1.63 & 1.95 & 1.76 & 1.59 \\
\hline $\begin{array}{l}\text { dipole moment } \\
10^{-30} \mathrm{C} \mathrm{m}\end{array}$ & 0.0 & 0.39 & 0.0 & 0.0 \\
\hline $\begin{array}{l}\text { quadrupole moment } \\
\qquad 10^{-40} \mathrm{Cm}^{2}\end{array}$ & 0.0 & -12.3 & -5.0 & 1.3 \\
\hline $\begin{array}{l}\text { enthalpy of vaporisation* } \\
\qquad \mathrm{kJ} \mathrm{mol}-1\end{array}$ & 6.49 & 6.03 & 5.58 & 7.18 \\
\hline $\begin{array}{l}\text { liquid density } \\
\qquad \mathrm{gcm}^{-3}\end{array}$ & 1.393 & 0.811 & 0.806 & 1.203 \\
\hline $\begin{array}{l}\text { solid density } \\
\mathrm{gcm}^{-3}\end{array}$ & 1.623 & 0.924 & 0.945 & 1.300 \\
\hline $\begin{array}{c}\text { critical point } T \\
\mathrm{~K}\end{array}$ & 150.86 & 132.91 & 126.20 & 154.57 \\
\hline $\begin{array}{l}\text { triple point point } T \\
\qquad \mathrm{~K}\end{array}$ & 83.78 & 68.14 & 63.15 & 54.35 \\
\hline
\end{tabular}

* from a liquid state 


\section{Lennard-Jones parameters for MC simulations}

Table S2. LJ potential parameters for adsorbate-adsorbate and adsorbate-DUT-49 interactions used.

\begin{tabular}{llllll}
\hline & $\mathrm{Ar}$ & $\mathrm{N}_{2}$ & $\mathrm{O}_{2}$ & $\mathrm{C}_{\mathrm{CO}}$ & $\mathrm{O}_{\mathrm{CO}}$ \\
\hline atom-atom $\sigma(\AA)$ & 3.40 & 3.31 & 3.02 & 3.43 & 3.12 \\
atom-atom $\epsilon / k_{B}(\mathrm{~K})$ & 119.80 & 36.00 & 49.00 & 52.89 & 30.22 \\
Atom of DUT-49 & $\sigma(\AA)$ & & $\epsilon / k_{B}(\mathrm{~K})$ & & \\
$\mathrm{C}$ & 3.47 & & 47.86 & & \\
$\mathrm{H}$ & 2.85 & & 7.65 & & \\
$\mathrm{~N}$ & 3.66 & & 38.98 & & \\
$\mathrm{O}$ & 3.12 & & 30.20 & & \\
$\mathrm{Cu}$ & 3.30 & & 2.52 & & \\
\hline
\end{tabular}

\section{MC snapshots at different pressures}

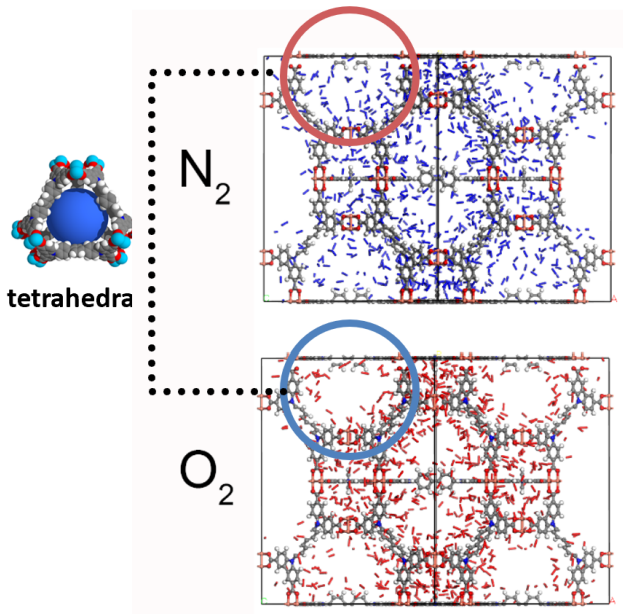

(a) $p / p^{0}=0.05$

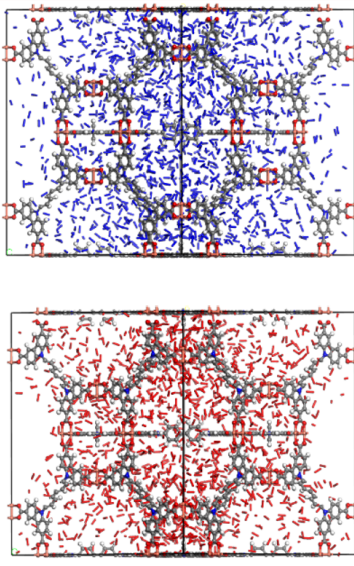

(b) $p / p^{0}=0.09$
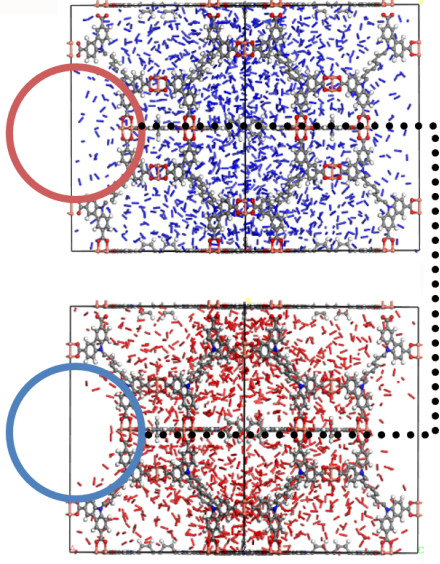

(c) $p / p^{0}=0.11$

Fig. S5. Snapshots of nitrogen (top) and oxygen (bottom) in DUT-49 pores at increasing partial pressures. The density of nitrogen in the material pores is seen to be much higher than that of oxygen at the same partial pressure, corresponding to a less localised phase. Highlighted are the tetrahedral and octahedral pores. 


\section{Dataset of deconvoluted nitrogen isotherms}
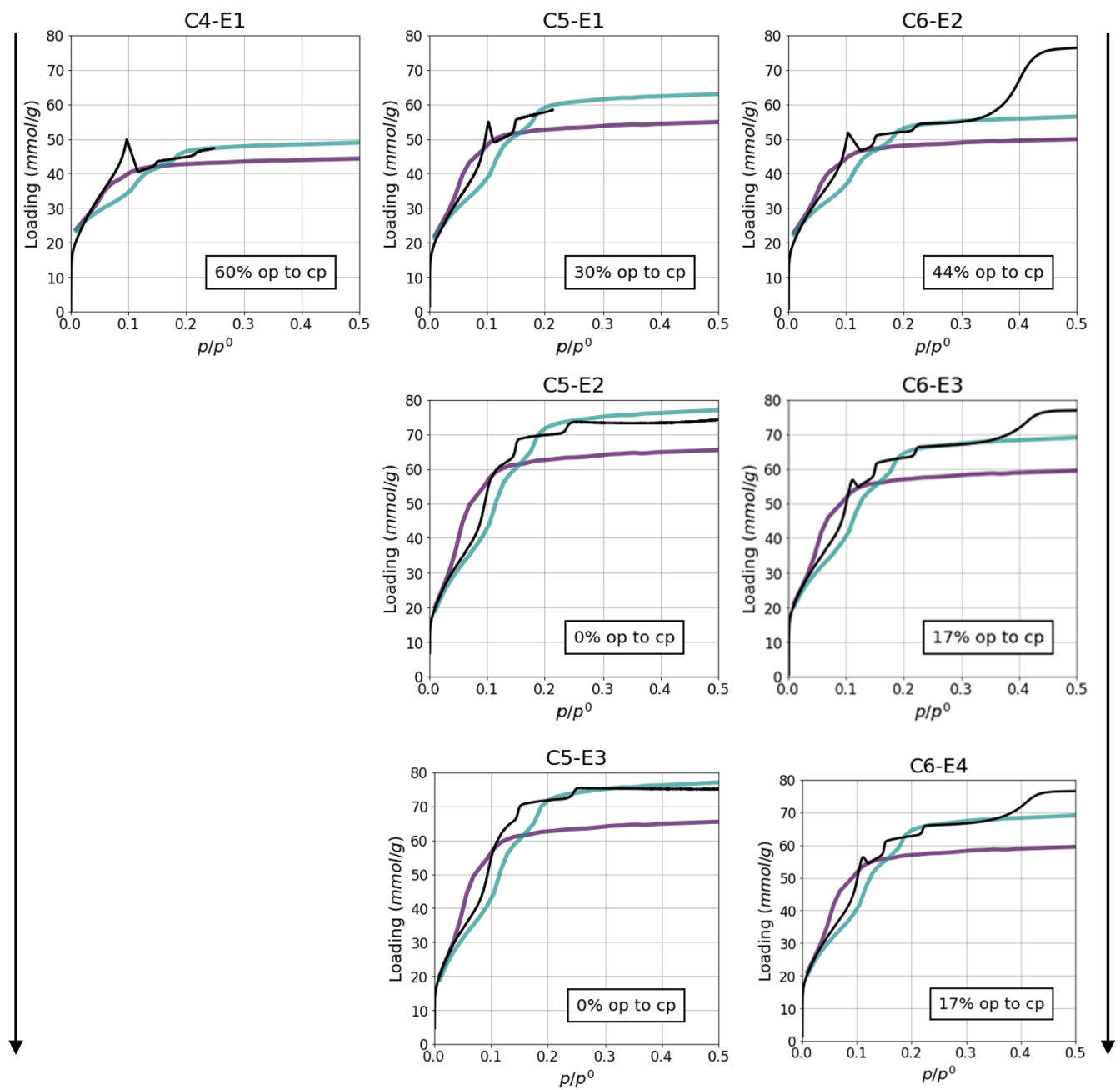

Fig. S6. Experimental nitrogen isotherms (black) and their deconvolution, presented as a function of cell number (C) and experiment number on each cell (E). Three cells are presented from left to right, with slight variations of material amount. Two repeats were performed on cell C5 and C6, with material re-activation under dynamic vacuum between experiments. Purple and green isotherms are linear contributions of $\mathbf{c p} / \mathbf{i p}$ and $\mathbf{c p} / \mathbf{o p}$ simulated isotherms, respectively. Calculated percentage of material undergoing complete op-cp transition is represented in the inset.

Table S3. Fraction of DUT-49 undergoing complete op-cp transition in nitrogen experiments.

\begin{tabular}{llll}
\hline & Cell 1 & Cell 2 & Cell 3 \\
\hline Experiment 1 & $60 \%$ & $30 \%$ & $44 \%$ \\
Experiment 2 & - & $0 \%$ & $17 \%$ \\
Experiment 3 & - & $0 \%$ & $17 \%$ \\
\hline
\end{tabular}




\section{Material colour change and degradation with adsorption}

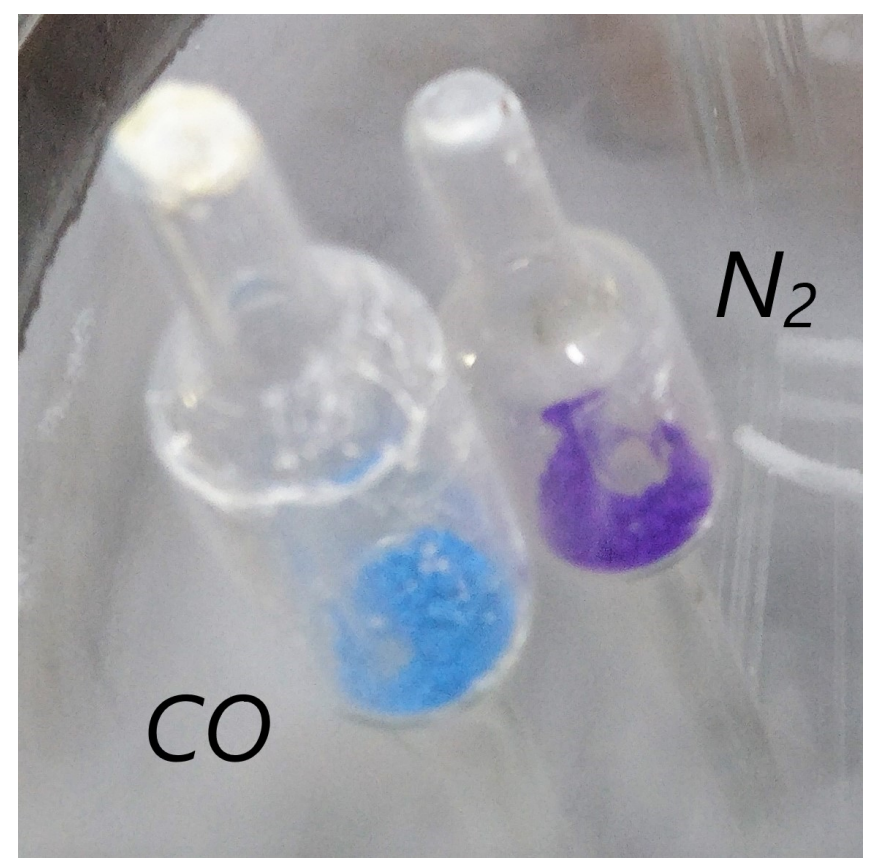

Fig. S7. Colour change upon exposure to carbon monoxide and nitrogen gas at saturation at $77 \mathrm{~K}$. Light blue colour is an indication of the change in the coordination sphere of the copper in the metal-organic polyhedra.

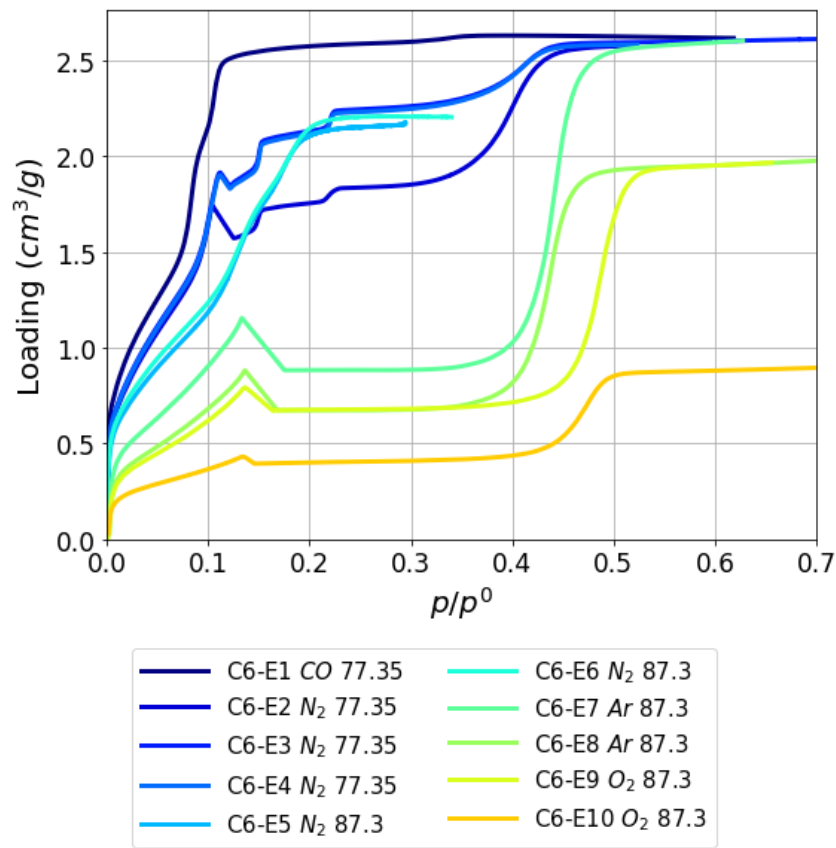

Fig. S8. Repeated experiments on a single cell, performed with standard re-activation between each run. Uptake is converted to a volumetric basis, by using the adsorbate liquid density at the experimental temperature. It can be seen that nitrogen adsorption does not appear to degrade the total uptake, while argon cycling (E 7 onwards) begins to lead to a progressive lowering of the total pore volume, corresponding to partial degradation of DUT-49. 
10. Time-resolved enthalpy data and integration at $77 \mathrm{~K}$
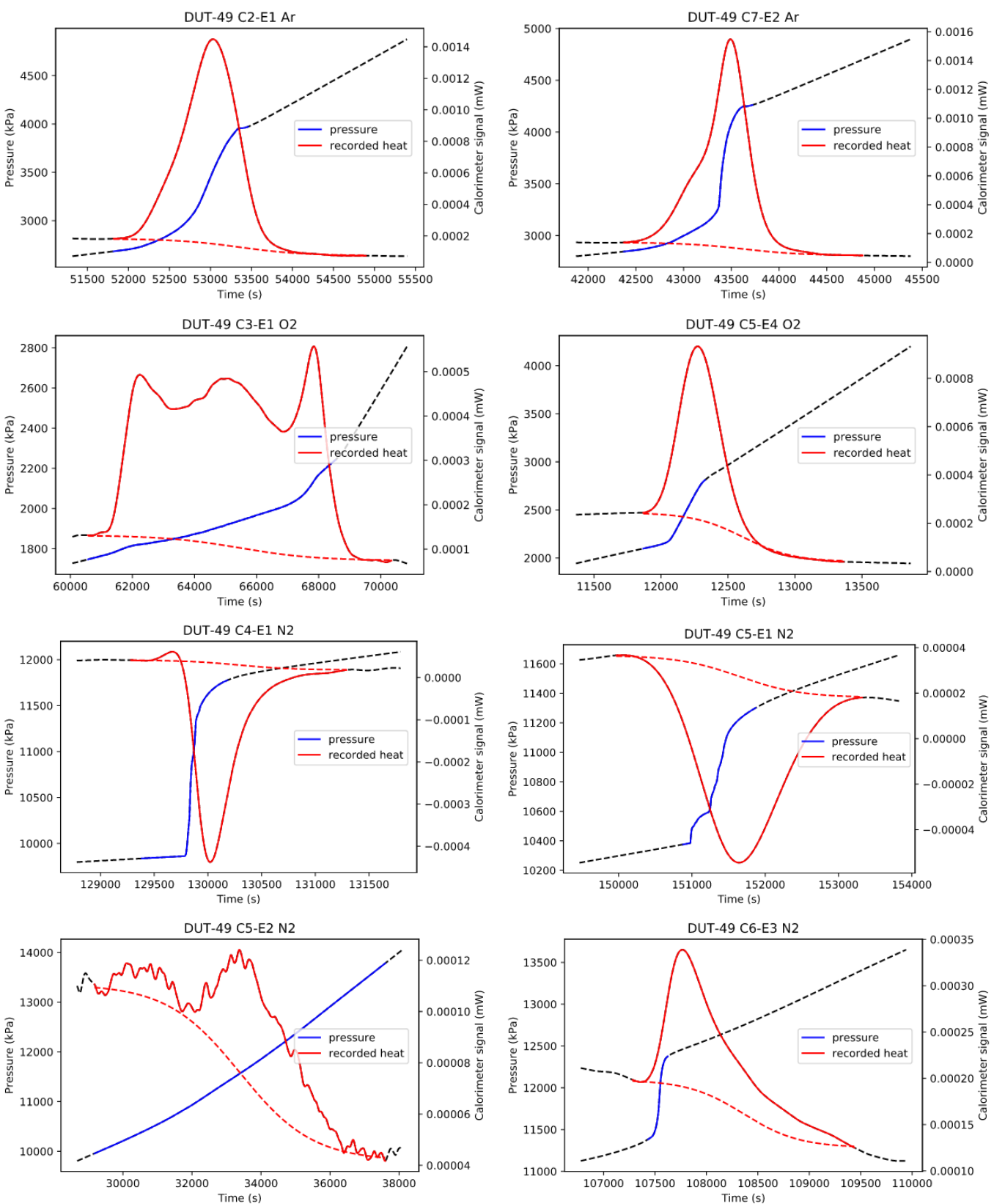

Fig. S9. Examples of time-resolved calorimetry peaks recorded during the NGA transition step at $77 \mathrm{~K}$ with argon (row 1), oxygen (row 2) and nitrogen (row 3 and 4 ). The blue and red curves are pressure and calorimeter signal, respectively. Pressure is seen to increase rapidly during a relatively short time span, with an associated peak in the recorded heat. An exothermic signal is observed for argon (row 1) and oxygen (row 2), with an endothermic one for nitrogen (row 3 ). When the structural transition with nitrogen is primarily op-ip, the signal is seen to become exothermic (row 4). 


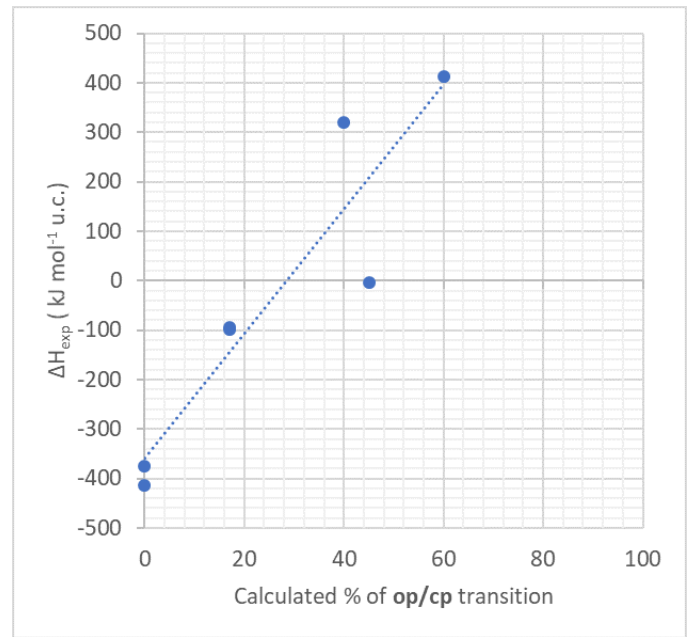

Fig. S10. Correlation between the amount of DUT-49 undergoing complete op-cp transition upon adsorption of nitrogen at $77 \mathrm{~K}$ and the enthalpy recorded for the NGA step of each datapoint. Each point corresponds to an isotherm in Fig. S6. 


\section{Calorimetry at $87 \mathrm{~K}$}
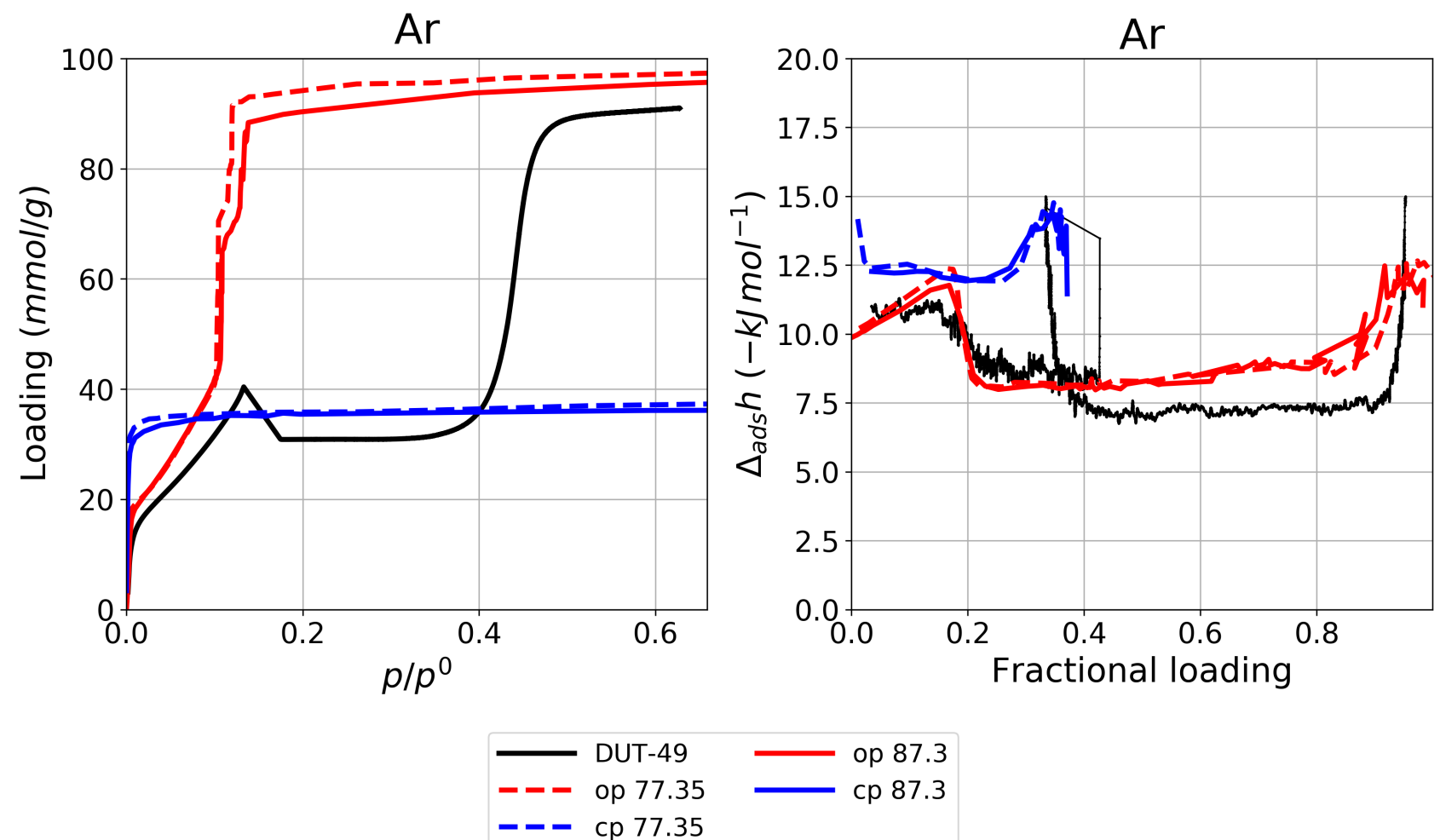

Fig. S11. Argon isotherms (left) and enthalpy curves (right) comparing $77 \mathrm{~K}$ and $87 \mathrm{~K}$ results. Experimental results are displayed in black, while simulated values are in blue and red for the $\mathrm{cp}$ and op curves, respectively. Curves in dotted line are results obtained at $77 \mathrm{~K}$, while the continuous line is for $87 \mathrm{~K}$. It can be seen that, while the simulated isotherms slightly overpredict the total uptake, there is excellent correspondence with recorded values. The enthalpy of adsorption is nearly unaffected by the increase in temperature, with complete overlap between the two curves.

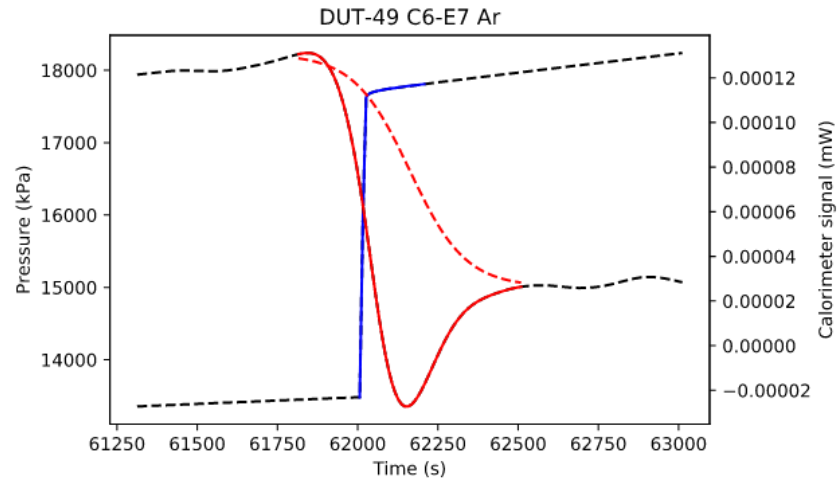

Fig. S12. Time-resolved calorimetry peaks recorded during the NGA transition step with argon at $87 \mathrm{~K}$. The blue and red curves are pressure and calorimeter signal, respectively. The NGA event is observed to become endothermic at this temperature. 